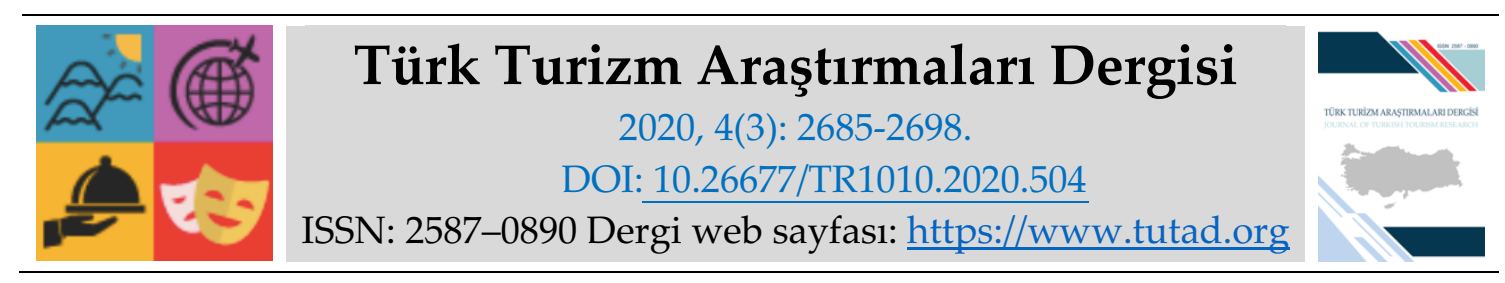

ARASTTIRMA MAKALESI

\title{
Turizm Bölümü Lisans Öğrencilerinin Sosyal Medya Bağımlılıkları ile Akademik Erteleme Davranışları Arasındaki İlişki
}

Dr. Öğr. Üyesi Handan ÖZÇELIK BOZKURT, Sinop Üniversitesi, Turizm İşletmeciliği ve Otelcilik Yüksekokulu, Sinop, e-posta: handanozcelikbozkurt@gmail.com ORCID: https://orcid.org/0000-0002-0035-3362

Öz

Bu çalışmada turizm bölümü lisans öğrencilerinin sosyal medya bağımlılıkları ile akademik erteleme davranışları arasındaki ilişkinin ortaya konması amaçlanmıştır. Çalışma kapsamında ilgili yazın taranmış ve veriler anket tekniği kullanılarak elde edilmiştir. Anket; sosyal medya bağımlılığı ve akademik erteleme davranışı olmak üzere iki adet ölçekten meydana gelmektedir. Araştırmanın örneklemini, Sinop Üniversitesi'nde öğrenim gören 348 öğrenci oluşturmaktadır. Elde edilen verilere, bilgisayar ortamında uygun istatistiki analiz programları kullanılarak; aritmetik ortalama, standart sapma ve korelasyon analizleri yapılmıştır. Araştırma dahilinde yapılan korelasyon analizi sonucunda öğrencilerin sosyal medya bağımlılık düzeyleri ile akademik erteleme davranışları arasında orta düzeyde pozitif yönlü anlamlı bir ilişki saptanmıştır. Dolayısıyla Sinop Üniversitesi turizm bölümü lisans öğrencilerinin sosyal medya bağımlılıkları arttıkça akademik erteleme davranışları artmaktadır.

Anahtar Kelimeler: Sosyal Medya Bağımlılı̆̆ı, Akademik Erteleme, Turizm.

Makale Gönderme Tarihi: 27.04.2020

Makale Kabul Tarihi: 01.07.2020

\footnotetext{
Önerilen Atıf:

Özçelik Bozkurt, H. (2020). Turizm Bölümü Lisans Öğrencilerinin Sosyal Medya Bağımlılıkları ile Akademik Erteleme Davranışları Arasındaki İlişki, Türk Turizm Araştırmaları Dergisi, 4(3): 2685-2698.
}

(C) 2020 Türk Turizm Araştırmaları Dergisi. 


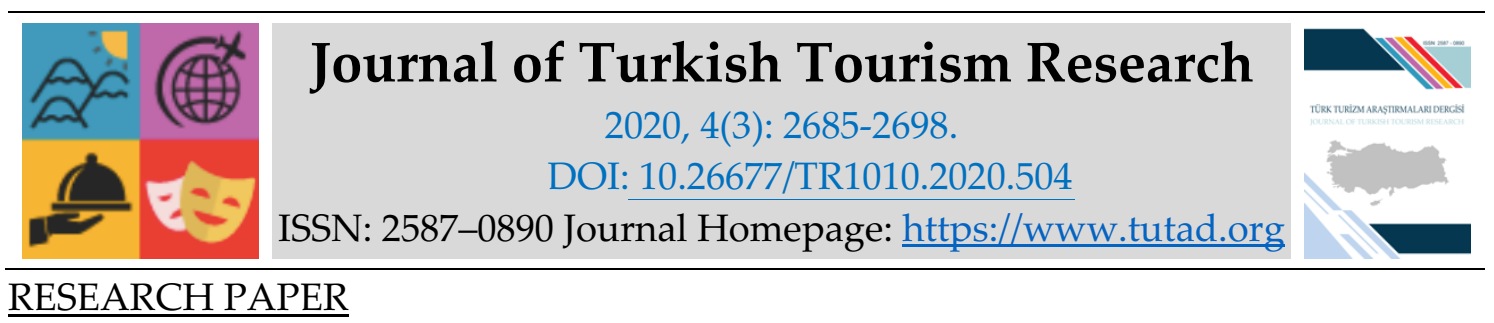

\title{
The Relationship Between Undergraduate Tourism Students' Social Media Addictions and Academic Procrastination Behaviors
}

Assistant Prof. Dr. Handan ÖZÇELIK BOZKURT, Sinop University, School of Tourism and Hotel Management, Sinop, e-mail: handanozcelikbozkur@@gmail.com

ORCID: https://orcid.org/0000-0002-0035-3362

\begin{abstract}
In this study, it is aimed to reveal the relationship between undergraduate tourism students' social media addictions and academic procrastination behaviors. Within the scope of the study, the relevant literature was reviewed and data were obtained using the survey technique. The survey consists of two scales: social media addiction and academic procrastination. The sample of the study consists of 348 students studying at Sinop University. The obtained data is by using appropriate statistical analysis programs in computer environment; arithmetic mean, standard deviation and correlation analysis were done. As a result of the correlation analysis conducted within the scope of the research, a medium positive relationship was found between students' social media addictions and academic procrastination behaviors. Therefore, as social media addictions of Sinop University tourism undergraduate students increase, academic procrastination behaviors increase.
\end{abstract}

Keywords: Social Media Addiction, Academic Procrastination, Tourism.

Received: 27.04 .2020

Accepted: 01.07.2020

\section{Suggested Citation:}

Özçelik Bozkurt, H. (2020). The Relationship Between Undergraduate Tourism Students' Social Media Addictions and Academic Procrastination Behaviors, Journal of Turkish Tourism Research, 4(3): 2685-2698.

(C) 2020 Türk Turizm Araştırmaları Dergisi. 


\section{Gíriş}

Dijital 2019 Küresel Değerlendirme Raporu'na göre, dünyada 4.39 milyar internet kullanıcısı vardır ve bu kullanıcıların 3.48 milyarı sosyal medya kullanıcısıdır (We are Social ve Hootsuite, 2019). Gelişen teknolojinin beraberinde sosyal medya kullanıcı sayısı gün geçtikçe katlanarak artmaktadır. Dünya çapında 210 milyon kadar insanın sosyal medya bağımlılığından mustarip olduğu tahmin edilmektedir (Longstreet ve Brooks, 2017: 73). Bu sayıya her geçen gün yeni bireylerin eklendiği düşünülmektedir. Facebook, Instagram, Twitter, Tik Tok gibi sosyal medya platformlarının artış göstermesinin yanı sıra kontrolsüz akıllı telefon kullanımı da bu büyümenin nedenleri arasında sıralanabilir. Sosyal medya bağımlılığı; iş performansı düşüklüğü (Zivnuska, Carlson, Carlson, Harris ve Harris, 2019: 746), zayıf öngörü, dürtüsellik (Turel, He, Brevers ve Bechara, 2018: 694), stres (Samaha ve Hawi, 2016: 321), siber aylaklık (Şahin, 2020: 629) gibi semptomlar göstermesinin haricinde akademik erteleme davranışının da bir öncülü olabilir.

Sosyal medyanın kontrolsüz şekilde kullanılması, gündelik işlere yoğunlaşmayı engelleme potansiyeline sahiptir. Sosyal medyayı hayatlarının bir parçası haline getiren ve beraberinde akademik yaşamlarına devam eden gençlerin, sosyal medya bağımlılık düzeylerinin ve akademik erteleme davranış düzeylerinin belirlenmesi önemlidir. Ayrıca bireyin üzerine düşen akademik sorumluluğu ötelemesi ya da yerine getirmemesinde sosyal medya kullanımının rolünü belirlemek de etki-tepki ilişkisinin saptanması bakımından gereklidir.

Güncel bir konu olan sosyal medya bağımlılığının akademik erteleme davranışı ile ilişkisini inceleyen çalışma sayısı sınırlıdır. Bununla birlikte söz konusu değişkenlerin birlikte incelendiği turizm alanında ulusal ve uluslararası yazında bir çalışmaya rastlanmamıştır. Bu bakımdan bu çalışmada turizm lisans öğrencilerinin sosyal medya bağımlılıklarının ve akademik erteleme davranışlarının düzeyi ve bu değişkenlerin birbirleri ile ilişkisini belirlemek amaçlanmıştır.

\section{SOSYAL MEDYA BAĞIMLILIĞI}

Aşırı derecede sosyal medya kullanımının, madde bağımlılığı ile benzer semptomlara yol açabileceğine işaret eden bilimsel kanıt sayısı her geçen gün artmaktadır (Andreassen, 2015: 175). Sosyal medya bağımlılı̆̆ı; davranışsal bağımlılık belirtisi olarak kendini gösteren, sosyal medya sitelerinin zorunlu kullanımıdır. Sosyal medya bağımlılı̆̆; dikkat çekme ihtiyacı, tolerans, çatışma, yoksunluk, nüks ve ruh hali değişikliği gibi psikolojik semptomlar gösterebilmektedir (Griffiths, 2005: 191). Daha önce yapılan araştırmaların çoğu belirli sosyal ağ sitelerinin (Facebook) kullanımına odaklanma eğilimindeydi. Ancak artık sosyal medya kullanımına yönelik seçenek sayısı oldukça çeşitlidir. Gençlerin son yıllarda Instagram, Twitter, Tiktok, Snapchat gibi sosyal medya platformlarını Facebook'tan daha yoğun şekilde kullandığı gözlenmektedir (Griffiths ve Kuss, 2017: 49).

Kadınlar (\%68) erkeklere (\%62) kıyasla daha fazla sosyal medya kullanmaktadır. Kadınların sosyal medyada geçirdikleri süre günlük minimum 46 dakika iken erkeklerin minimum 31 dakika çevrimiçi kaldıkları tahmin edilmektedir (Perrin, 2015). İstatistikler internet kullanıcılarının çoğunun sosyal medya kullanıcıları olduğunu göstermektedir (Corbeil ve Corbeil, 2011: 13). Sosyal medya bireylerin çok çeşitli insanlarla etkileşime girmesine izin verse de bu yüzeysel ve yapay etkileşimler yüz yüze iletişimin yerini alma konusunda yetersiz kalmaktadır. İnternet ve sosyal ağ platformlarının aşırı kullanımı bireyin ailesi, arkadaşları ve sevdikleri arasındaki bağlantıları zayıflatabilmektedir (Pantic, 2014: 652; Yellowlees ve Marks, 2007: 1447). Özellikle gençler sürekli çevrimiçi ağın kültürel normuyla bütünleşmiş 
durumdadırlar. Ebeveynlerin güvenlik endişeleri, farklı ortamlar arayan gençlerin sanal ortama yönelmesinde etkili olmuştur (Boyd, 2014: 252). Çünkü çevrimiçi olmak, sokakta dolaşmaktan daha güvenli görülmekte ve ebeveynler genellikle teknolojiyi evde kullanmanın normal ve sağlıklı olduğunu varsaymaktadırlar (Griffiths ve Kuss, 2017: 49). Son yıllarda yapılan çalışmalar sosyal medyada bilgi paylaşmanın gençlerde yaşam doyumu ve yalnızlığı artırdığını, ileri yaştaki yetişkinlerde ise durumun tam tersi şekilde olduğunu göstermiştir (Teo ve Lee, 2016: 351).

Sosyal medyaya kontrolsüz şekilde yönelen gençler, bu sitelerde geçirdikleri zamanın farkında değiller ve zaman içerisinde gerçek yaşamın sorumluluklarını görmezden gelmeye başlamaktadırlar. Gerçek yaşamı ve ilişkileri sanal perspektiften yorumlamaya başlayan bireyler, bir noktadan sonra gerçek hayattan kopma eğilimi göstermektedirler. Gündelik hayatta arkadaş edinmekte zorlanan genç bir kişinin sosyal medyada çok fazla arkadaşı olabilmektedir (Kırık vd., 2015: 112). Bu sitelerdeki etkinlikler zamanla ruh halinde değişiklikler, hoşa giden duygular ve uyuşukluk etkisi (ruh hali değişikliği) yaratmaktadır. Dolayısıyla insan aynı duyguları elde etmek için sosyal ağ bağlantılarına daha fazla zaman ayırmaya başlamaktadır (Griffiths ve Kuss, 2017: 50). Depresyon, çekingenlik, iletişim becerilerindeki zayıflıklar, korku ve sosyal fobi, kötümserlik, bireyin kendisinin veya dünyanın geleceği hakkında endişelerinin var olması onu sosyal medyaya yöneltmektedir (Chak ve Leung, 2004: 559; Günüç, 2009: 31).

Çok sayıda çalışma, internet ve sosyal ağ sitelerinde bağımlılıklar da dahil olmak üzere teknolojik bağımlılıkların stres, kaygı ve depresyon ile pozitif ilişki içerisinde olduğunu; akademik performansla negatif ilişkisinin olduğunu ve bunların hepsinin yaşam doyumunu olumsuz yönde etkilediğini göstermiştir (Kuss, Griffiths, Karila ve Billieux, 2014: 4026; Lepp, Barkley ve Karpinski, 2014: 343; Kabasakal, 2015: 296; Samaha ve Hawi, 2016; Hawi ve Samaha, 2016: 86; Şahin, 2017: 120). Kırcaburun (2016: 68) bireydeki benlik saygısının azalmasıyla birlikte günlük internet kullanımının arttığını, günlük internet kullanımının artmasıyla birlikte ise depresyonun arttığını saptamıştır. Aynı çalışmada sosyal medya bağımlılığının artmasıyla günlük internet kullanımının arttığı da gözlenmiş̧tir. Longstreet ve Brooks (2017: 73) yaşam doyumunun internet ve sosyal medya bağımlılığı üzerinde önemli etkisi olduğunu gözlemlemişlerdir. Dolayısıyla bireyin hayatında var olan köklü sorunlar bireyin yaşam doyumunu azaltmakla birlikte onu internet ve sosyal medya bağımlılığına yöneltebilmektedir.

Satıcı ve Uysal (2015: 185) 311 lisans öğrencisinin katılımıyla gerçekleştirdikleri çalışmalarında sorunlu Facebook kullanımının yaşam doyumunu azalttığını tespit etmişlerdir. 82 Amerikalı katılımcının yer aldığı bir örneklemde ise Facebook kullananların refah ve yaşam doyumlarının daha fazla olduğu gözlenmiştir (Kross vd., 2013: 3). Almanya'da 583 Facebook kullanıcısı ile yapılan bir araştırmada, çevrimiçi kullanıcıları pasif olarak takip eden kişilerin sosyal karşılaştırma ve kıskançlık duyguları yaşadıklarını ve bunun da yaşam doyumlarını azalttığını göstermiştir (Krasnova, Wenninger, Widjaja ve Buxmann, 2013: 10). Kırık vd., (2015: 114) yaşları 13 ile 19 arasında değişen 271 öğrencinin katılımıyla gerçekleştirdikleri çalışmalarında cinsiyetin sosyal medya bağımlılığı faktörü üzerinde anlamlı bir etkisinin olmadığını, yaş faktörünün artmasıyla birlikte sosyal medya bağımlılık düzeyinin de arttığını tespit etmişlerdir. Çalışanlar üzerine yapılan bir araştırmada sosyal medya bağımlılı̆ıını artmasıyla birlikte dikkat eksikliğinin de arttı̆̆ 1 ve günlük stres kaynaklarıyla baş etmede daha çok duyguların ön plana çıtığı gözlenmiştir (Sriwilai ve Charoensukmongkol, 2016: 427). 


\section{AKADEMIKK ERTELEME DAVRANIŞI}

Erteleme, hemen hemen herkesin çeşitli zamanlarda sergilediği bir davranış durumudur. Erteleme davranışı, çeşitli sonuçlar doğurmanın yanında pek çok faktöre bağlı olarak ortaya çıkabilmektedir. Bireyin yapması gerektiğinin farkında olduğu, belki yapmayı da istediği ancak sürekli harekete geçmekte zorlandığı faaliyetler bütünü erteleme davranışını tanımlamaktadır (Senecal, Koestner ve Vallerand, 1995: 607). Noran (2000)'a göre erteleme eğilimi olan kişiler yapmaları gereken işin farkında ve işi yapabilecek donanımdadır; ancak daha farklı işlere yöneldikleri, zamanlarını daha küçük işlerde harcadıkları veya daha zevk veren etkinliklere ağırlık verdikleri için "erteleme" davranışı sergilerler. Akademik erteleme ise akademik görevleri yerine getirme konusunda ertelemeye bağlı olarak zamanlama problemi yaşama durumudur (Rothblum, Solomon ve Murakami, 1986: 387). Akademik erteleme eğilimi olan bireylerin görevden kaçınmalarına neden olan dört bilişsel etken vardır. Bunlar; görevi gerçekleştirmek için kalan sürenin fazla tahmin edilmesi ya da görev için gereken zamanın hafife alınması; gelecekte görev için gerekli motivasyonun sağlanacağının düşünülmesi; görev için gerekli olan duygusal uyumun sağlanacağına inanılması ve çalışmak için modunda olmanın gerekliliğine inanılmasıdır (Noran, 2000).

Ashraf, Malik ve Musharraf (2019: 65)'a göre akademik erteleme ve akademik stres değişkenleri arasında pozitif yönlü bir ilişki mevcuttur. Genel yeterlilik düzeyi düştükçe erteleme davranışı artış göstermektedir (Ferrari, Parker ve Ware, 1992: 495). Akademik öz-yeterlilik ve benlik saygisı erteleme davranışı ile negatif ilişki içerisindedir (Klassen, Krawchuk ve Rajani, 2008: 915). Aydoğan ve Özbay (2012: 5) düşük benlik saygısının akademik erteleme davranışına neden olduğunu tespit etmişlerdir. Balkıs ve Duru (2010: 165)'ya göre de akademik erteleme davranışı genel benlik saygısını azaltırken, akademik başarıyı da düşürmektedir. Çelik ve Odacı (2015: 31) ise akademik başarı azaldıkça akademik erteleme davranışının arttığını saptamıştır. Ayrıca çalışmalarında bireydeki öz- yeterlilik inancının azalmasıyla birlikte akademik erteleme davranış eğiliminin arttığını tespit etmişlerdir. Motivasyon düzeyi düşük ve konsantre olmakta zorlanan öğrencilerin akademik erteleme davranışları daha fazla olmaktadır (Balkıs, Duru, Buluş ve Duru, 2006: 64; Akinsola, Tella ve Tella, 2007: 365). Ekşi ve Dilmaç (2010: 440) ise öğrencilerin yaşamış oldukları sürekli kaygıdan dolayı erteleme eğilimi gösterdiklerini saptamıştır. Başarısızlık kaygısının buna neden olabileceği düşünülmektedir. Ayrıca görevden kaçma isteği de belirleyiciler arasındadır (McGregor ve Eliot, 2002; Onwuegbuzie, 2004: 15). Kandemir (2014: 191) sorumluluk duygusu arttıkça erteleme davranışının azaldığını gözlemlemiştir.

Erkek öğrencilerin kız öğrencilerden daha fazla akademik erteleme davranışı sergilediklerini gözlemleyen çalışma sayısı yoğunluktadır (Flett, Blankstein, Hewitt ve Koledin, 1992: 91; Prohaska, Morrill, Atiles ve Perez, 2000: 125; Özer, Demir ve Ferrari, 2009: 241; Aydoğan ve Özbay, 2012: 5; Çelikkaleli ve Akbay, 2013: 237; Çelik ve Odacı, 2015: 37). Akademik erteleme davranışında cinsiyet değişkeninin belirleyici rol oynamadığını tespit eden çalışmalar da mevcuttur (Onwuegbuzie, 2004: 15; Watson 2001: 149; Akinsola, Tella ve Tella, 2007: 367). Solomon ve Rothblum (1984) ise kız öğrencilerin erteleme davranışlarının genellikle başarısızlık korkusundan kaynaklandığını vurgulamışlardır.

\section{İlgili Çalışmalar}

Demir ve Kutlu (2018: 322) internet bağımlılığı ile birlikte gençlerde akademik erteleme davranışının da arttığını saptamışlardır. Yang, Asbury ve Griffiths (2018: 166) kontrolsüz akıllı telefon kullanımının akademik erteleme ve akademik kaygı faktörlerini artırdığını 
gözlemlemişlerdir. Akkuş (2018: 83) öğrencilerin Facebook kullanım sıklı̆̆ının akademik erteleme davranışlarını artırdığını tespit etmiştir. Ayrıca bu çalışmada anne baba tutumunun Facebook kullanımı sıklığı konusunda belirleyici olmadığı saptanmıştır. Can ve Zeren (2019: 1012) lise öğrencilerinin katılımıyla gerçekleştirdikleri çalışmalarında internet bağımlılığının akademik ertelemeyi önemli düzeyde artırdığını gözlemlemişlerdir. Demir ve Kutlu (2017: 98) da lise öğrencilerine yönelik çalışmalarında internet bağımlılığının akademik ertelemeye neden olduğunu ve akademik başarıyı olumsuz yönde etkilediğini ortaya koymuşlardır.

Durak (2018: 7) sosyal medyanın yanlış kullanımı ile sosyal kaygı, öz denetim ve akademik erteleme davranışı arasında anlamlı ilişki olduğunu gözlemlemiştir. Ekşi, Turgut ve Sevim (2019: 739) öz- kontrolün sosyal medya bağımlılığı üzerinde önemli düzeyde etkili olduğunu; düşük öz-kontrolün erteleme davranışına neden olduğunu; öz-kontrolü düşük ve erteleme davranışı sergileyen bireylerde ise sosyal medya bağımlılığı belirtilerinin gözlendiğini belirtmiştir. Gür, Bakırcı, Karakaş, Bayoğlu ve Atlı (2018: 72) üniversite öğrencilerine yönelik araştırmalarında, erkek öğrencilerin daha fazla akademik erteleme davranışı sergilediğini ve sosyal medya bağımlılığı yüksek olan öğrencilerin akademik erteleme eğilimlerinin daha çok olduğunu tespit etmişlerdir.

Hinsch ve Sheldon (2013: 502) sosyal medya kullanımının kısa vadede insanı mutlu ettiğine ancak zamanla yaşam doyumunu azaltarak erteleme davranışını da artırdığına dikkat çekmiştir. Malik ve Rafiq (2016: 93) nevrotik bozukluk, sosyal yalnızlık ve bireylerin çevrimiçi iletişim kurduğu kişilerden aldığı sosyal desteğin internet bağımlılığına neden olduğunu ve bu durumun akademik erteleme davranışını tetiklediğini saptamışlardır. Przepiorka, Błachnio ve DíazMorales (2016: 59) kadınların ve gençlerin Facebook'u daha yoğun şekilde kullandıklarını ayrıca genel ve durumsal ertelemenin önemli düzeyde Facebook kullanımından kaynaklandığını tespit etmişlerdir. Şahin (2020: 629) de Facebook kullanıcısı öğrencilerin daha fazla akademik erteleme davranışı gösterdiğini gözlemlemiştir. Rozgonjuk, Kattago ve Taht (2018: 191) derslerde sosyal medya ile ilgilenen öğrencilerin erteleme davranışı gösterdiğini dolayısıyla problemli akıllı telefon kullanımının bu durumu tetiklediğini vurgulamıştır. Tekin (2019: 36) öğretmenlerin katılımıyla gerçekleştirdiği çalışmasında; öğretmenlerin \%53'ünün orta ve yüksek düzeyde sosyal medya bağımlısı olduğunu ve genel erteleme davranışlarıyla sosyal medya bağımlılıkları arasında pozitif yönlü bir ilişki olduğunu saptamıştır. Yurdakoş ve Biçer (2019: 243) de internet bağımlılığının akademik erteleme davranışını yordadığı sonucuna ulaşmıştır. Odacı (2011: 1109) ve Ahmad, Yusoq ve Aji (2018: 25) ise sosyal medya bağımlılığı ile akademik erteleme davranışı arasında anlamlı bir ilişki bulunmadığını tespit etmişlerdir.

Bu bilgiler doğrultusunda araştırmanın hipotezi aşağıdaki şekilde geliştirilmiştir;

Hı: Turizm bölümü lisans öğrencilerinin sosyal medya bağımllıkları ile akademik erteleme davranışları arasında pozitif yönlü anlamlı bir ilişki vardır.

\section{YÖNTEM}

$\mathrm{Bu}$ araştırmanın temel amacl, Sinop Üniversitesi turizm bölümü lisans öğrencilerinin sosyal medya bağımlılığı ve akademik erteleme davranışları arasındaki ilişkiyi ortaya koymaktır. Yapılan ilgili yazın taraması sonucu ulusal ve uluslararası yazında söz konusu iki değişken arasındaki ilişkiyi turizm alanında inceleyen çalışmaya rastlanmamıştır. 
Araştırma modeli betimsel niteliktedir. Betimsel modelde; mevcut bir problemi, bu problemle ilişkili durumları, değişkenleri ve değişkenlerin arasındaki ilişkiyi incelemek amaçlanmaktadır (Ural ve Kılıç, 2006).

Araştırma kapsamında sosyal medya bağımlılı̆̆ını ölçmek amacıyla Brown'un (1997: 13) davranışsal bağımlılık bileşeni ölçeği ve cep telefonu bağımlılık ölçeğine ( Walsh, White, McD Young, 2010: 194) dayanılarak Hawi ve Samaha (2011: 576) tarafından geliştirilen "sosyal medya bağımlılık ölçeği" kullanılmıştır. Öğrencilerin akademik erteleme davranışı düzeylerini ölçümlemek amacıyla Çakıcı (2003) tarafından geliştirilen "akademik erteleme davranış ölçeği" kullanılmıştır. Her iki ölçek de 5'li Likert tipinde olup sosyal medya bağımlılı̆̆ı ölçeğinde "(1) Hiç Katılmıyorum - (5) Tamamen Katılıyorum" şeklinde derecelendirilirken, akademik erteleme davranışı ölçeği "(1) Beni Hiç Yansıtmıyor - (5) Tamamen Beni Yansıtıyor" şeklinde derecelendirilmiştir.

Anket formunun ilk bölümünde sosyal medya bağımlılığı ve akademik erteleme davranışı ölçek ifadeleri yer alırken ikinci kısımda demografik değişkenlere yönelik sorular yer almaktadır. Ölçeklere ilişkin güvenilirlik kat sayılarına bakıldığında sosyal medya bağımlılığı ölçeğinin Cronbach's Alpha katsayısı $(\alpha)=0,84$ ve akademik erteleme davranışı ölçeğinin Cronbach's Alpha katsayısı $(\alpha)=0,88$ olarak ölçülmüştür. Dolayısıyla ölçeklerin güvenilir düzeyde olduğu gözlenmiştir (Büyüköztürk, 2008).

Araştırma evreni, Sinop Üniversitesi Turizm İşletmeciliği ve Otelcilik Yüksekokulu öğrencilerinden oluşmaktadır. Yüksekokulun toplam öğrenci sayısı 803'tür. Bu sayı araştırma evrenini temsil etmektedir. Örneklem büyüklügünün hesaplanması için "Sample Size Calculator" kullanılmıştır (http://www.surveysystem.com/sscalc.htm). Güven düzeyi \%95 güven aralığ1 ise 5 'tir. Hesaplama sonucu örneklem büyüklüğü 260 olarak belirlenmiştir. Araştırmanın uygulaması 2019 güz döneminde gerçekleştirilmiş ve toplam 350 anketten 348 tanesi değerlendirmeye alınmıştır. Söz konusu 2 anket ise eksik doldurulduğu için değerlendirme dışı bırakılmıştır. Öğrencilere ilişkin demografik bilgilerin belirlenmesi amacıyla frekans dağılımları incelenmiş, ölçek maddelerine ilişkin ortalama değerleri hesaplanmış, değişkenler arasındaki ilişkinin ortaya konması amacıyla korelasyon analizi yapılmıştır.

\section{BULGULAR}

Araştırmaya katılan 348 katılımcıdan \%60,6'sı kadın, \%39,4'ü erkektir. Katılımcıların yaş ortalaması ise 21,34 düzeyindedir. Araştırmaya katılanların büyük çoğunluğu (\%29,5) 4. Sınıf öğrencileridir.

Ankette yer alan sosyal medya bağımlılığı ölçek maddelerine ilişkin aritmetik ortalama ve standart sapma bilgileri Tablo 1'de yer almaktadır. Tablo 1'e göre ilgili ölçekte "sosyal medyayı ne kadar süre kullandığımın farkındayım" ifadesi 3,90 ortalama ile en yüksek puana sahiptir. "Sosyal medya kullanımım nedeniyle çeoremdekilerle tartışma yaşadığım olur" ifadesi ise 2,01 ortalama ile en düşük puana sahiptir. Ölçeğin genel ortalamasına bakıldığında ise öğrencilerin sosyal medya bağımlılık düzeylerinin 2,86 puanla orta düzeyde olduğu görülmektedir. 
Tablo1: Sosyal Medya Bağımlılı̆̆ı Değişkeninin Aritmetik Ortalama ve Standart Sapma Değerleri

\begin{tabular}{|l|c|c|}
\hline İfadeler & $\begin{array}{c}\text { Aritmetik } \\
\text { Ortalama }\end{array}$ & $\begin{array}{c}\text { Standart } \\
\text { Sapma }\end{array}$ \\
\hline Sosyal medyayı kullanamadığımda aklım hep orada kalıyor. & 2,83 & 1,17 \\
\hline Sosyal medyayı sık sık belirli bir sebep olmadan kullanıyorum. & 3,44 & 1,28 \\
\hline $\begin{array}{l}\text { Sosyal medya kullanımım nedeniyle çevremdekilerle tartı̧ma yaşadığım } \\
\text { olur. }\end{array}$ & 2,01 & 1,24 \\
\hline $\begin{array}{l}\text { Sosyal medyaya erişim ihtiyacı hissettiğimde yaptığım başka ne olursa olsun } \\
\text { bırakıyorum. }\end{array}$ & 2,21 & 1,14 \\
\hline $\begin{array}{l}\text { Sosyal medya kullanırken başkalarıyla bağlantı halinde olduğumu } \\
\text { hissediyorum. }\end{array}$ & 3,18 & 1,27 \\
\hline Sosyal medyayı ne kadar süre kullandığımın farkındayım. & 3,90 & 1,26 \\
\hline Sosyal medyaya erişememe düşüncesi beni üzüyor. & 2,70 & 1,27 \\
\hline Sosyal medya kullanımımı azaltamıyorum. & 2,64 & 1,35 \\
\hline GENEL ORTALAMA & $\mathbf{2 , 8 6}$ & $\mathbf{1 , 2 4}$ \\
\hline
\end{tabular}

Tablo2: Akademik Erteleme Davranışı Değişkeninin Aritmetik Ortalama ve Standart Sapma Değerleri

\begin{tabular}{|l|c|c|}
\hline İfadeler & $\begin{array}{c}\text { Aritmetik } \\
\text { Ortalama }\end{array}$ & $\begin{array}{c}\text { Standart } \\
\text { Sapma }\end{array}$ \\
\hline Derslerime düzenli olarak çalışırım. & 2,95 & 1,01 \\
\hline Ödevlerimi/projelerimi genellikle son belirlenen tarihte yetiştiririm. & 3,52 & 1,25 \\
\hline Daha keyifli şeyler yapmak için ders çalışmayı erken bırakırım. & 3,29 & 1,18 \\
\hline Sınavlardan önce konuları tekrar etmeye zamanım kalır. & 3,21 & 1,08 \\
\hline Ne zaman dersin başına otursam aklıma yapmam gereken başka işler gelir. & 3,67 & 0,99 \\
\hline Önemli olsalar bile sınavlara çalışmayı gereksiz yere son güne bırakırım. & 3,26 & 1,20 \\
\hline Derslere hazırlanarak gelirim. & 2,52 & 1,04 \\
\hline Sıkıcı derslere çalışmayı son ana bırakırım. & 3,73 & 1,17 \\
\hline Herhangi bir dersle ilgili verilen okumaları derse okumuş olarak gelirim. & 2,63 & 1,01 \\
\hline $\begin{array}{l}\text { Ders çalışırken bir şey yapmak, birisiyle konuşmak, çay ya da kahve içmek } \\
\text { vb. için sık sık ara veririm. }\end{array}$ & 3,50 & 1,04 \\
\hline Ödevlerimi/projelerimi zamanında teslim ederim. & 3,66 & 1,19 \\
\hline $\begin{array}{l}\text { Tarihi önceden bildirilmiş olsa bile sınav günü yaklaştığında önceliği } \\
\text { olmayan başka işlerle uğraştığım olur. }\end{array}$ & 3,30 & 1,08 \\
\hline Kendime bir ders çalışma programı hazırlamışsam ona uyarım. & & \\
\hline Önemli derslere çalışmayı bile son güne bırakırım. & 2,79 & 1,28 \\
\hline Çalışmayı son güne bıraktığım için başarısız olduğum derslerim olur. & 3,22 & 1,20 \\
\hline Ödevlerimi/projelerimi zamanında yetiştiremem. & 3,17 & 1,26 \\
\hline Bir sınavdan önce sınavla ilgili konuları her yönüyle çalışmış olurum. & 2,38 & 1,38 \\
\hline Ödevlerimi/projelerimi yapmayı önemsiz gerekçelerle son güne bırakırım. & 3,05 & 0,96 \\
\hline $\begin{array}{l}\text { Ben derslerime çalışmayı son ana bırakan ancak bir daha ki sefere çalışmaya } \\
\text { zamanında başlayacağım diyen bir öğrenciyim. }\end{array}$ & 3,82 & 1,26 \\
\hline GENEL ORTALAMA & 3,31 & 1,29 \\
\hline
\end{tabular}

Tablo 2'ye göre ilgili ölçekte "sıkıcı derslere çalışmayı son ana bırakırım" ifadesi 3,73 ortalama ile en yüksek puana sahiptir. "Ödevlerimi/projelerimi zamanında yetiştiremem" ifadesi 2,38 ortalama ile en 
düşük puana sahiptir. Ölçeğin genel ortalamasına bakıldığında ise öğrencilerin akademik erteleme davranışlarının 3,15 puanla orta düzeyde olduğu görülmektedir.

Tablo 3: Değişkenler Arası Korelasyon Matrisi

Değișkenler $(\mathrm{n}=348) \quad$ Sosyal Medya Bağımlılığı $\quad$ Akademik Erteleme Davranıșı

Sosyal Medya Bağımlılığı 1

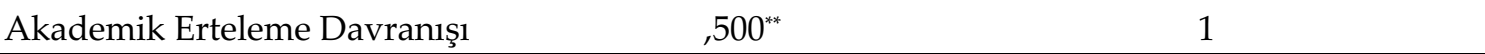

Korelasyon katsayısının 0,00-0,30 arasında olması düşük, 0,30- 0,70 arasında olması orta, 0,701,00 arasında olması ise yüksek düzeyde anlamlı bir ilişkinin varlığını ifade etmektedir (Büyüköztürk, 2008). Tablo 3'e göre araştırmada kullanılan ölçeklerden Sosyal Medya Bağımlılığı ile Akademik Erteleme Davranışı arasında (pearson korelasyon katsayısı $=0,500$ pozitif yönlü orta düzeyde anlamlı bir ilişki bulunmaktadır. Dolayısıyla " $\mathrm{H}_{1}$ : Turizm bölümü lisans öğrencilerinin sosyal medya bağımlılıkları ile akademik erteleme davranışları arasında pozitif yönlü anlamlı bir ilişki vardır" hipotezi kabul edilmiştir.

\section{SONUÇ ve ÖNERILER}

Sosyal medya bağımlılığı ile akademik erteleme davranışı arasındaki ilişkiyi belirlemek amacıyla yapılan bu çalışmanın örneklemi Sinop Üniversitesi turizm bölümünde öğrenim gören 348 lisans öğrencisinden oluşmaktadır. Araştırmada öğrencilerin sosyal medya bağımlılıkları ile akademik erteleme davranışları arasında pozitif yönlü ve orta düzeyde bir ilişki olduğu saptanmıştır. Böylelikle $\mathrm{H}_{1}$ hipotezi, elde edilen bulgular doğrultusunda kabul edilmiştir. Bu sonuç, ilişkiyi inceleyen çalışmaların çoğu ile benzerlik gösterirken (Malik ve Rafiq, 2016: 93; Demir ve Kutlu, 2018: 322; Gür vd., 2018; Şahin, 2020: 629), birkaç çalışma ile de (Odacı, 2011: 1109; Ahmad vd., 2018: 25) örtüşmemektedir.

Daha önce sosyal medya bağımlılığı ve akademik erteleme davranışı değişkenleri sınırlı sayıda tek başına veya birlikte incelenmiş ancak turizm bölümü öğrencilerine yönelik her iki değişkenin etkişimini inceleyen herhangi bir çalışmaya rastlanmamıştır. Ayrıca konu son derece güncel ve araştırmaya açıktır. Bu çalışma, turizm bölümü lisans öğrencilerinin sosyal medya bağımlılıkları ve akademik erteleme davranışlarına ilişkin bulguları ortaya koymakla birlikte; gelişmekte olan ilgili yazına da katkı sağlama amacı taşımaktadır.

Elde edilen bulgular, turizm bölümü lisans öğrencilerinin sosyal medya bağımlılık düzeylerinin orta, akademik erteleme davranışlarının ise benzer şekilde orta düzeyde olduğunu; ancak akademik erteleme davranışlarının sosyal medya bağımlılık düzeylerinden daha yüksek olduğunu göstermiştir. Gelişen teknoloji sosyal medya bağımlılığının başlıca sebebidir. Bunun yanında depresyon, çekingenlik, iletişim becerilerindeki zayıflıklar, korku ve sosyal fobi, kötümserlik, bireyin kendisinin veya dünyanın geleceği hakkında endişelerinin var olması onu sosyal medyaya yöneltmektedir (Chak ve Leung, 2004: 559; Günüç, 2009: 27). Dolayısıyla gençleri sosyal medya bağımlılığına iten faktörlerin derinlemesine incelenmesi ve medya kuruluşları, paneller veya hastanelerin ruh sağlığı birimlerinde konu hakkında daha detaylı çalışmaların yapılması gerekliliği ortaya çıkmaktadır. Özellikle gelecek hakkında endişelerin varlığı 
öğrencilerin turizm sektöründe istihdam edilebilirlik algılarını ya da iş güvencesizliği algılarını akla getirmektedir.

Akademik erteleme davranışının varlığı bireyde genel yeterlilik, akademik öz- yeterlilik, benlik saygısı, motivasyon, konsantrasyon gibi psikolojik faktörlerin düşük olmasına bağlanmaktadır (Ferrari, Parker ve Ware, 1992: 495; Klassen, Krawchuk ve Rajani, 2008: 915). Ayrıca öğrencilerin sürekli kaygı yaşamaları, görevden kaçma istekleri ve sorumluluk duygularının düşük olması akademik erteleme davranışlarını artırmaktadır (McGregor ve Eliot, 2002: 381; Onwuegbuzie, 2004: 15; Ekşi ve Dilmaç, 2010: 439; Kandemir 2014: 191). Dolayısıyla araştırmaya katılan öğrencilerin akademik erteleme davranışlarını psikolojik nedenler, kariyer kararlarında yapılan hatalar, öğrenim gördükleri bölüme yönelik ilgi düzeylerinin düşük olması ve sorumluluk kazandırma noktasında ebeveynlerin gerekli çaba sarf etmemesi ile ilişkilendirilebilir. Bu noktada ilk çocukluk (2-6 yaş) döneminden itibaren sorumluluk bilincinin geliştirilmesi için ebeveynlere önemli görevler düşmektedir. Eğitim kurumlarınca ilkokuldan itibaren psikolojik danışmanlık hizmetinin etkin biçimde verilmesi, gençlerin ilgi alanları ile örtüşen üniversite bölümlerini seçmelerinin teşvik edilmesi, öğrencilerin akademik başarı puanlamalarında dağıtımsal adaletin sağlanması son derece önemlidir.

Günümüzün eğitim gören gençleri, geleceğin istihdam kaynaklarıdır. Dolayısıyla sosyal medyaya bağımlı iş görenlerin işletmeye, işverene ve çalıştığı sektöre vereceği zararlar büyüktür. Özellikle emek-yoğun yapıda olan ve insan ilişkilerinin son derece önemli olduğu turizm sektöründe iş görenin birincil önceliği sosyal medya değil, işletmede hizmet verdiği misafirler olmalıdır. Öte yandan, öğrenciler akademik erteleme davranışı sergileyerek sektör hakkında yeterli akademik bilgi edinemeyebilirler. Dolayısıyla turizm bölümü öğrencilerinin sosyal medya bağımlılıkları ve akademik erteleme davranışları dolaylı olarak turizm sektörüne de zarar verebilir.

Araştırma sonucunda elde edilen bulgular, öğrencilerin sosyal medya bağımlılıklarının ve akademik erteleme davranışlarının varlığını ortaya koymanın yanı sıra sosyal medya bağımlılığının akademik erteleme davranışı ile pozitif yönde ilişki içerisinde olduğunu da ortaya koymaktadır. İlerleyen zamanlarda mevcut değişkenlerin farklı evren ve örneklemler ile incelenmesi, değişkenlere ilişkin öncül ve ardılların belirlenmesi ve buna ilişkin çalışmalara ağırlık verilmesi faydalı olacaktır.

\section{KAYNAKÇA}

Ahmad, A., Yusoq, N. I. and Aji, Z. M. (2018). The Relationship Between Social Media Addiction and Academic Performance based on Personality Characteristics. Knowledge Management International Conference (KMICe) 2018, 25 -27 July 2018, Miri Sarawak, Malaysia.

Akinsola, M. K., Tella, A., and Tella, A. (2007). Correlates of Academic Procrastination and Mathematics Achievement of University Undergraduate Students. Eurasia Journal of Mathematics, Science \& Technology Education, 3(4): 363-370.

Akkuş, R. (2018). 8.Sınıf Öğrencilerinin Facebook Tutumu İle Akademik Erteleme Davranışları Arasındaki İlişkinin İncelenmesi (Balıkesir İli Merkez İlçeler Örneği). Yüksek Lisans Tezi. Balıkesir Üniversitesi, Sosyal Bilimler Enstitüsü, Eğitim Bilimleri Ana Bilim Dalı, Eğitim Programları ve Öğretim Bilim Dalı, Balıkesir. 
Andreassen, C. S. (2015). Online Social Network Site Addiction: A Comprehensive Review. Current Addiction Reports, 2(2): 175-184.

Ashraf, M., Malik, J. A., and Musharraf, S. (2019). Academic Stress Predicted by Academic Procrastination Among Young Adults: Moderating Role of Peer Influence Resistance. Journal of Liaquat University of Medical \& Health Sciences, 18(1): 65-70.

Aydoğan, D. ve Özbay, Y. (2012). Akademik Erteleme Davranışının Benlik Saygısı, Durumluluk Kaygı, Özyeterlik Açısından Açıklanabilirliğinin İncelenmesi, Pegem Eğitim ve Öğretim Dergisi, 2 (3): $1-9$.

Balkıs, M., Buluş, M., Duru, E. ve Duru, S. (2006). Üniversite Öğrencilerinde Akademik Erteleme Eğiliminin Çeşitli Değişkenler Açısından İncelenmesi. Ege Eğitim Dergisi, 7(1), 57-73.

Balkıs, M. ve Duru, E. (2010). Akademik Erteleme Eğilimi, Akademik Başarı İlişkisinde Genel ve Performans Benlik Saygısının Rolü. Pamukkale Üniversitesi Eğitim Fakültesi Dergisi, 27, 159-170.

Boyd, D. (2014). It's Complicated: The Social Lives of Networked Teens. Yale: Yale University Press.

Brown, I. (1997). A Theoretical Model of the Behavioural Addictions-Applied to Offending. (Editors) J. Hodge, M. Mcmurran \& C. R. Hollin: In Addicted to Crime? (Vol. The Wiley Series in Offender Rehabilitation, Pp. 15-63). Chichester: Wiley

Büyüköztürk, Ş. (2008). Veri Analizi El Kitabı. Ankara: Pegem Yayınları

Can, S.ve Zeren, Ş. G (2019). Ergenlerin Akademik Erteleme Davranışlarını Açılamada İnternet Bağımlılı̆̆ı ve Temel Psikolojik İhtiyaçların Rolü. Çukurova Üniversitesi Eğitim Fakültesi Dergisi, 48(2): 1012-1040

Chak, K. and Leung, L. (2004). Shyness and Locus of Control as Predictors of Internet Addiction and Internet Use. Cyberpsychology \& Behavior, 7(5): 559-570.

Corbeil, J.R., and Corbeil, M.E. (2011). The Birth of a Social Networking Phenomenon. (Editor.) C. Wankel: In Educating Educators with Social Media: Cutting-Edge Technologies in Higher Education (pp. 13-32). Bingley, West Yorkshire, UK: Emerald.

Çakıc1, D.Ç. (2003). Lise ve Üniversite Öğrencilerinde Genel Erteleme ve Akademik Erteleme Davranışının İncelenmesi. Yayınlanmamış Yüksek Lisans Tezi. Ankara Üniversitesi, Ankara.

Çelik, Ç. ve Odacı, H. (2015). Akademik Erteleme Davranışının Bazı Kişisel ve Psikolojik Değişkenlere Göre Açılanması, Hacettepe Üniversitesi Eğitim Fakültesi Dergisi, 30 (3): 31-47.

C,elikkaleli, O. ve Akbay, S. E. (2013). Üniversite Öğrencilerinin Akademik Erteleme Davranışı, Genel Yetkinlik İnancı ve Sorumluluklarının İncelenmesi. Ahi Evran Üniversitesi Kırşehir Eğitim Fakültesi Dergisi, 14(2): 237-254.

Demir, Y. ve Kutlu, M. (2017). İnternet Bağımlılığı, Akademik Erteleme ve Akademik Başarı Arasındaki İlişkiler. The Journal of Academic Social Science Studies, 61, 91-105.

Demir, Y. and Kutlu, M. (2018). Relationships Among Internet Addiction, Academic Motivation, Academic Procrastination and School Attachment in Adolescents, International Online Journal of Educational Sciences, 10(5): 315-332.

Durak, H.Y. (2018). Modeling of Variables Related to Problematic Internet Usage and Problematic Social Media Usage in Adolescents. Current Psychology, 1-13. https://link.springer.com/content/pdf/10.1007/s12144-018-9840-8.pdf Erişim: 08. 02. 2020. 
Ekşi, H., ve Dilmaç, B. (2010). Üniversite Öğrencilerinin Genel Erteleme, Karar Vermeyi Erteleme ve Akademik Erteleme Düzeylerinin Sürekli Kaygı Açısından İncelenmesi. Uludă̆ Üniversitesi Ĕ̆itim Fakültesi Dergisi 23(2): 433-450.

Ekşi, H., Turgut, T., and Sevim, E. (2019). The Mediating Role of General Procrastination Behaviors in the Relationship Between Self-Control and Social Media Addiction in University Students. Addicta: The Turkish Journal on Addictions, 6, 717-745.

Ferrari, J. R.; Parker, J. T. and Ware, C. B. (1992). Academic Procrastination: Personality Correlates with Myers-Briggs Types, Self-Efficacy, and Academic Locus of Control. Journal of Social Behavior and Personality, 7, 495-502.

Flett, G.L., Blankstein, K.R., Hewitt, P.L., and Koledin, S. (1992). Components of Perfectionism and Procrastination in College Students. Journal of Social Behavior and Personality, 20(2): 85-94.

Griffiths, M. (2005). A 'Components' Model of Addiction within A Biopsychosocial Framework. Journal of Substance Use, August, 10(4): 191-197.

Griffiths, M. D. and Kuss, D. J. (2017). Adolescent Social Media Addiction (Revisited). Education and Health, 35(3): 49-52.

Günüç, S. (2009). İnternet Bağımlılık Ölçeğinin Geliştirilmesi ve Bazı Demografik Değğişkenler İle İnternet Bağımlılığı Arasındaki İlişkilerin İncelenmesi. Yayımlanmış Yüksek Lisans Tezi. Yüzüncü Yıl Üniversitesi Sosyal Bilimler Enstitüsü, Van.

Gür, S. H., Bakırcı, Ö., Karakaş, B., Bayoğlu, F. ve Atli, A. (2018). Üniversite Öğrencilerinin Sosyal Medya Bağımlılı̆̆ının Akademik Erteleme Davranışları Üzerindeki Etkisi. İnönü Üniversitesi Ĕ̆itim Bilimleri Enstitüsü Dergisi, 5(10): 68-77.

Hawi, N. S., and Samaha, M. (2016). To Excel or Not to Excel: Strong Evidence on the Adverse Effect of Smartphone Addiction on Academic Performance. Computers \& Education, 98, 81-89.

Hawi, N. S., and Samaha, M. (2017). The Relations Among Social Media Addiction, Self-Esteem, and Life Satisfaction in University Students. Social Science Computer Review. 35(5): 576-586.

Hinsch, C., and Sheldon, K. M. (2013). The Impact of Frequent Social Internet Consumption: Increased Procrastination and Lower Life Satisfaction. Journal of Consumer Behaviour, 12(6): 496505.

Kabasakal, Z. (2015). Life Satisfaction and Family Functions As-Predictors of Problematic Internet Use in University Students. Computers in Human Behavior, 53(1): 294-304.

Kandemir, M. (2014). Reasons of Academic Procrastination: Self-Regulation, Academic SelfEfficacy, Life Satisfaction and Demographics Variables. Procedia. Social and Behavioral Sciences, 152(1): 188-193.

Kırcaburun, K. (2016). Self-Esteem, Daily Internet Use and Social Media Addiction as Predictors of Depression among Turkish Adolescents. Journal of Education and Practice, 7(24), 64-72.

Kırık, A. M., Arslan, A., Çetinkaya, A., and Gül, M., (2015). A Quantitative Research on the Level of Social Media Addiction Among Young People in Turkey. International Journal of Science Culture and Sport (IntJSCS), 3(3), 108-122.

Klassen, R. M., Krawchuk, L. L. and Rajani, S. (2008). Acaemic Procrastination of Undergraduates: Low Self-Efficacy to Self-Regulate Predicts Higher Levels of Procras-Tination. Contemporary EducationalPsychology,33,915-931. 
Krasnova, H., Wenninger, H., Widjaja, T., and Buxmann, P. (2013). Envy on Facebook: A Hidden Threat to Users' Life Satisfaction? (Editors) R. Alt \& B. Franczyk: 11th International Conference on Wirtschaftsinformatik (92, pp. 1-16). Leipzig, Germany.

Kross, E., Verduyn, P., Demiralp, E., Park, J., Lee, D. S., Lin, N., ...Ybarra, O. (2013). Facebook Use Predicts Declines in Subjective Well-Being in Young Adults. PloS One, 8(8), e69841.

Kuss, D., Griffiths, M., Karila, L., and Billieux, J. (2014). Internet Addiction: A Systematic Review of Epidemiological Research for the Last Decade. Current Pharmaceutical Design, 20(1): 4026-4052.

Lepp, A., Barkley, J. E., and Karpinski, A. C. (2014). The Relationship Between Cell Phone Use, Academic Performance, Anxiety, and Satisfaction with Life in College Students. Computers in Human Behavior, 31, 343-350.

Longstreet, P. and Brooks, S. (2017). Life Satisfaction: A Key to Managing Internet \& Social Media Addiction. Technology in Society (50), 73-77.

Malik, A. U., and Rafiq, N. (2016). Exploring the Relationship of Personality, Loneliness, and Online Social Support with Interned Addiction and Procrastination. Pakistan Journal of Psychological Research, 31 (1): 93-117.

McGregor, H. A., and Elliot, A. J. (2002). Achievement Goals as Predictors of AchievementRelevant Processes Prior to Task Engagement. Journal of Educational Psychology, 94, 381-395.

Noran, F. Y. (2000). Procrastination Among Students In Institutes of Higher Learning: Chalenges for K-Economy. http://www.mahdzan.com/papers/ procrastinate/ Erişim: 17. 02. 2020.

Odac1, H. (2011). Academic Self-Efficacy and Academic Procrastination as Predictors of Problematic Internet Use in University Students. Computers \& Education, 57(1): 1109-1113.

Onwuegbuzie, A. J. (2004). Academic Procrastination and Statistics Anxiety. Assessment \& Evaluation in Higher Education, 29(1): 3-19.

Özer, B. U., Demir, A., and Ferrari, J. R. (2009). Exploring Academic Procrastination among Turkish Students: Possible Gender Differences in Prevalence and Reasons. Journal of Social Psychology, 149(1), 241-257.

Pantic, I. (2014). Online Social Networking and Mental Health. Cyberpsychology, Behavior, and Social Networking, 17(10): 652-657.

Perrin, A. (2015). Social Networking Usage: 2005-2015. Pew Research Center. http://www. pewinternet.org/2015/10/08/2015/Social-Networking-Usage-2005-2015/ Erişim: 11. 02. 2020.

Prohaska, V., Morrill, P., Atiles, I., and Perez, A. (2000) Academic Procrastination by Nontraditional Students. Journal of Social Behavior \& Personality, 15(5): 125-135.

Przepiorka, A., Błachnio, A., and Díaz-Morales, J. F. (2016). Problematic Facebook Use and Procrastination. Computers in Human Behavior, 65(1): 59-64.

Rothblum, E. D., Solomon, L. J., and Murakami, J. (1986). Affective, Cognitive, and Behavioral Differences Between High and Low Procrastinators. Journal of Counseling Psychology, 33(1): 387394.

Rozgonjuk, D., Kattago, M., and Taht, K. (2018). Social Media Use in Lectures Mediates the Relationship Between Procrastination and Problematic Smartphone Use. Computers in Human Behavior, 89(1), 191-198.

Samaha, M., and Hawi, N. S. (2016). Relationships Among Smartphone Addiction, Stress, Academic Performance, and Satisfaction with Life. Computers in Human Behavior, 57(1): 321-325. 
Satıcı, S. A., and Uysal, R. (2015). Well-Being and Problematic Facebook Use. Computers in Human Behavior, 49(1): 185-190.

Senecal, C., Koestner, R., and Vallerand, R. J. (1995). Self-Regulation and Academic Procrastination. The Journal of Social Psychology, 135(1): 607-619.

Sriwilai, K., and Charoensukmongkol, P. (2016). Face It, Don't Facebook It: Impacts of Social Media Addiction on Mindfulness, Coping Strategies and the Consequence on Emotional Exhaustion. Stress \& Health, 32(4): 427-434.

Şahin, C. (2017). The Predictive Level of Social Media Addiction for Life Satisfaction: A Study on University Students. Turkish Online Journal of Educational Technology, 16(1): 120-125.

Şahin, Y. L. (2020). Facebook Sosyal A ̆g Kullanıcılarının Akademik Erteleme Davranışları İle Eğitsel Ortamlardaki Siber Aylaklık Durumlarının İncelenmesi. Kırşehir Eğitim Fakültesi Dergisi, 21(1), 629-666.

Tekin, O. (2019). Öğretmenlerin Sosyal Medya Bağımlılık Seviyelerinin Genel Erteleme Davranışlarıyla İlişkisi. Türkiye Eğitim Dergisi. 4(1), 36-47.

Teo, W. J. S., and Lee, C. S. (2016). Sharing Brings Happiness? Effects of Sharing in Social Media Among Adult Users. (Editörler) A. Morishima, A. Rauber \& C. L. Liew Digital Libraries: InKnowledge, Information, and Data in an Open Access Society: 18th International Conference on Asia-P acific Digital Libraries, ICADL 2016, Tsukuba, Japan, December 7-9, 2016, Proceedings (pp. 351-365). Cham: Springer International Publishing.

Turel O, He Q Brevers D, and Bechara A. (2018). Delay Discounting Mediates the Association Between Posterior Insular Cortex Volume and Social Media Addiction Symptoms. Cogn Aff Behav, Cognitive, Affective, \& Behavioral Neuroscience (2018) 18:694-704.

Ural, A. ve Kılıç, İ. (2006). Bilimsel Araştırma Süreci ve Spss ile Veri Analizi. Ankara: Detay Yayıncilik.

Yang, Z. Y., Asbury, K. and Griffiths, M.D. (2018). An exploration of Problematic Smartphone Use Among Chinese University Students: Associations with Academic Anxiety, Academic Procrastination, Self-Regulation and Subjective Well-Being. Journal of Mental Health and Behavioral Addictions, 7(1): 166-166.

Yellowlees, P. M., and Marks, S. (2007). Problematic Internet use or Internet addiction?. Computers in Human Behavior 23(1): 1447-1453.

Yurdakoş, K. ve Biçer, E. B. (2019). İnternet Bağımlılık Düzeyinin Akademik Ertelemeye Etkisi: Sağlık Yönetimi Öğrencileri Üzerine Bir Araştırma. Yüzüncü Yıl Üniversitesi Eğitim Fakültesi Dergisi, 16(1): 243-278

Walsh, S. P., White, K. M., and McD Young, R. (2010). Needing to Connect: The Effect of Self and Others on Young People's Involvement with Their Mobile Phones. Australian Journal of Psychology, 62(1): 194-203.

Watson, D. C. (2001). Procrastination and the Five-Factor Model: A Facet Level Analysis. Personality and Individual differences, 30(1): 149-159.

Zivnuska S., Carlson, J. R., Carlson D.S., Harris R.B., and Harris K. J (2019) Social Media Addiction and Social Media Reactions: The Implications for Job Performance. J Soc Psychol 159(6):746-760. 